
Multidisciplinary SCIENTIFIC JOURNAL OF MARITIME RESEARCH

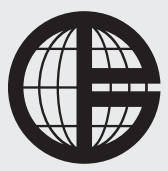
University of Rijeka
FACULTY OF MARITIME STUDIES
Multidisciplinarni
znanstveni časopis
POMORSTVO

\title{
Conceptual model of the ferry que management system in ferry ports in the Republic of Croatia
}

\author{
Dino Županovićn ${ }^{1}$ Luka Grbić ${ }^{1}$, Marijan Cukrov \\ ${ }^{1}$ University of Zadar, Maritime Department, Mihovila Pavlinovića 1, 23000 Zadar, Croatia, e-mail: dino.zupanovic@unizd.hr; lugrbic@unizd.hr \\ ${ }^{2}$ Intermodal Transport Cluster - KIP, Tina Ujevića 52A, 51000 Rijeka, Croatia, e-mail: cukrov@shortsea.hr
}

\section{ABSTRACT}

This paper proposes a model for optimizing the ferry traffic and the traffic demand at the macroscopic level by using information technology (IT) and the existing tourist amenities as a key element for achieving harmonization of supply and demand, i.e. optimization of the assessed system. Proposed approach differs from the other/present models because it includes the application of the macroscopic, instead of the microscopic (local) approach, i.e. harmonization of the ferry infrastructure demand from the place of its origin (road border crossings) to the place of its operation, i.e. the ferry infrastructure, and not solely in particular segments of the ferry infrastructure.

\section{ARTICLE INFO}

Review article

Received 17 September 2020

Accepted 3 December 2020

\author{
Key words: \\ Optimization \\ Ferry \\ Que \\ Supply \\ Demand \\ Management \\ Ports \\ Monitoring \\ Information
}

\section{Introduction}

The ferry traffic in the Republic of Croatia represents the only link that allows the transport of vehicles and passengers between the mainland and the Croatian islands. This is of extreme importance given the fact that all major Croatian islands are permanently inhabited throughout the year. But, although being of strategic importance for the life and further development of Croatian islands, its economic efficiency has often been put aside. In addition to the strategic importance of maintaining normal living conditions on the islands, during the summer months in the Republic of Croatia there has been a significant increase on the ferry infrastructure load, primarily ferries (RO-PAX vessels) and ferry terminals. The consequence of this seasonality, i.e. the relatively short duration of increased demand and the disproportion in the number of vehicles in this period has been an additional challenge in optimizing the use of the ferry infrastructure.
The analysis of the existing system [17] has clearly shown that the complexity of the ferry traffic optimization in the Republic of Croatia is primarily defined by three elements - indented coastline (the geographical impact), tourist season/seasonality (the traffic impact) and discrepancy in the current infrastructure (ferry ports infrastructure) and market demands (road vehicles - traffic influence, i.e. traffic infrastructure). Due to their specific properties, each of the elements imposes significant, often mutually exclusive, limits in the process of the optimisation. As mentioned above, the most prominent example is the increasing demand for ferry infrastructure (regarding the vehicles capacity) during summer, since the number (capacity) of ferries is limited in that period. The most effective respond to the increasing demands would be the increased number of ferries employed (solely in the ferry ports that can support the larger number of ferries). However, this is not economically justified solution due to the reduced number of vehicles during off-season. Thus, these factors influence the amount of discrepancy in the 
current infrastructure and the market demands of the analysed system.

The previous researches on this topic have further supported the thesis on the peculiarity of the observed system in the Republic of Croatia, where one study [17] and one master thesis [18] were conducted at the macroscopic and microscopic level, one study was conducted at the microscopic level [15], and two master's [2,4] and one doctoral thesis [10] mostly at the theoretical level. The importance of this topic has been confirmed by two strategic documents of the Government of the Republic of Croatia "Maritime Development Strategy and Integrated Maritime Policy of the Republic of Croatia for the period from 2014 to 2020" [5] and "Transport Development Strategy of the Republic of Croatia for the period from 2017 to 2030" [6].

This paper proposes a model for optimizing the ferry traffic and the traffic demand at the macroscopic level by using information technology (IT) and the existing tourist infrastructure (facilities, attractions, etc.) as a key element for achieving harmonization of supply and demand, i.e. optimization of the assessed system. The proposal for the optimization-harmonization of the ferry system load in the Republic of Croatia has resulted from former researches and facts obtained $[17,18]$. The preceding studies on the application of Information Technologies (IT) in tourism have shown the readiness of both end [1,7-9,11-13] and infrastructural $[1,3,8,9]$ users for their application, which is the keystone to the model presented in this paper.

This approach differs from the present models because it includes the application of the macroscopic, instead of the microscopic (local) approach, i.e. harmonization of the ferry infrastructure demand from the place of its origin (road border crossings) to the place of its operation, i.e. the ferry infrastructure, and not solely in particular segments of the ferry infrastructure.

\section{Description and elements of the analysed system}

In order to determine the solution for the optimization of the ferry traffic at the macroscopic level, it was necessary to determine its basic elements, and their mutual connections. Hierarchically, the identified elements have been divided into:

- Economic elements categorized in terms of revenue growth and reduced expenditure incurred by the system employment.

- Technological elements and information technologies (IT) that are used or might be used in the process of optimisation.

- Technical elements regarding the system infrastructure have also been considered.

For the quality development of the system, it is necessary to observe the presented hierarchy and describe its elements in the opposite direction, i.e. from the technical elements to the economic elements. Taking everything into consideration, it is possible to identify five technical elements by analysing the ferry traffic system:

1. The main road border crossings used by vehicles entering the Republic of Croatia in demand for the ferry infrastructure.

2. The main ferry ports and berths with the regular service to the islands.

3. Number of ferries operating between the mainland and the islands.

4. Main roads (routes) connecting the main road border crossings and the main ferry ports and berths, and

5. Tourist infrastructure (facilities, attractions, etc.) in the Republic of Croatia (in the immediate vicinity of the main road routes, with enough capacity to accommodate the road vehicles).

The analysis of the above-mentioned elements has shown a direct connection between the first four elements, while the fifth element has no direct connections with the other elements in the current system [17]. In other words, there are no evidence of clear and intentional connection with the other elements at this stage of the system. Due to this fact there is a high possibility to improve or optimize the analysed system by including the existing tourist infrastructure in order to harmonize the relationship between ferry infrastructure supply and demand. Although the national parks have been considered in this model proposal due to their distinctive recognizability, basically it is very easy to replace or expand the tourist (infrastructure) offer with any other type of tourist facility, which is very advisable for the future development of the system, i.e. the optimization of the ferry and tourist infrastructure.

In this classification, the road border crossings, the ferry infrastructure, and the tourist infrastructure (national parks) represent junctions linked by the road infrastructure (Figure 6). In addition, it should be emphasized that this paper classifies ferries as a stationary infrastructure (although they do not belong to this category) because this model does not include the change of their current number due to high seasonality (economic inefficiency), but it proposes the optimisation based on their routes and schedules thus directly influencing the change in the ferries' capacity. All these elements represent the static elements of the system. In other words, both the ferry services and the elements form the system's supply chain. The road vehicles in the system represent the entities, whereas their movement between the elements of supply chain makes the system dynamic. At the same time, they are representing the element of demand in the system.

As stated before, due to the system's inelastic supply (seasonality), the optimization-harmonization of supply and demand has been implemented by optimizing the dynamic element of the system, i.e. by the redistribution of the vehicle movements between the static (technical) elements of the system.

The need for harmonization of the road traffic flow in the current system has ascended from the fact that the 


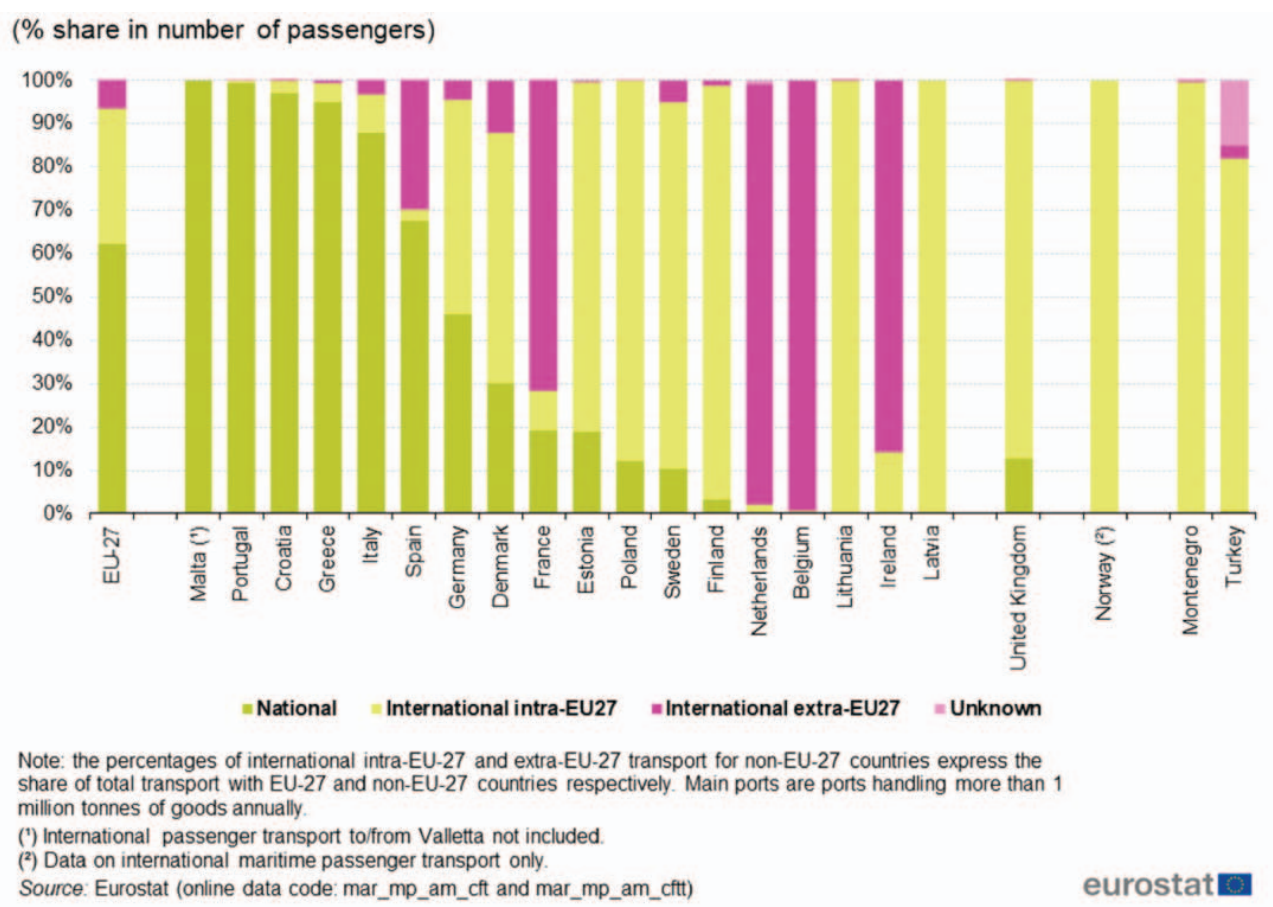

Figure 1 Seaborne transport of passengers (excluding cruise passengers) between the main ports in the reporting country and their partner ports grouped by the main geographical areas, 2018 [19]

ferry ports and berths, especially those located in the urban areas, are limited in the ferry infrastructure capacity (ferry and ferry ports capacity) which results in the vehicle queues and prolonged waiting time. Queues occur as a result of the increased number of the vehicles, i.e. entities in the system which during the tourist season put a pressure on the traffic infrastructure thus disabling its transport capacity meet the growth in demands. The formation of the queues has an additional negative effect on all ferry ports located in the urban areas, since the negative effect of the queues in the ferry ports, affects the urban road network, causing additional losses in the system.

The complexity of the problem is even more highlighted if we take into account the fact that the majority of the seaborne passenger transport in the EU is carried out between ports situated in the same country (61\%), reflecting the dominant role of national ferry services in the EU seaborne passenger transport as shown on Figure 1. In general, countries with busy ferry connections to and from well-populated islands will have both a large volume of seaborne passenger transport and a high share of national maritime passenger transport. This applies to the two leading maritime passenger countries, Italy and Greece, as well as countries like Portugal, Croatia and Spain [19].

\section{Structure of the optimisation-harmonization of demand on ferry infrastructure system}

Technological elements necessary for the development of the system denote IT and Intelligent Transportation
Systems (ITS) as part of it that would enable the establishment and maintenance of the optimization system in the operational mode as well as it's logical organization. The technological elements in the analysed model have been (logically) classified into three levels - the Infrastructural, the User and the Integration level, whereas Integration level comprises both User and Infrastructural levels, User level comprises Infrastructural level. Only the integration of all three levels enables the optimal operation of proposed optimization model (Figure 2 and Figure 3). More detailed hierarchical and relational connectivity between systems' technological elements is presented on Figure 3. Those will be discussed in the paragraphs to follow.

Pursuant to Figure 4, there are four subsystems at the Infrastructural level:

- Ferry infrastructure monitoring and information system.

- System for monitoring and providing information on the condition of the road infrastructure.

- System for monitoring and providing information on the condition of the road border crossings.

- System of monitoring and providing information on tourist infrastructure in the Republic of Croatia.

Another essential and very important technological element of the system (although, technically speaking, it does not belong to this category), is the will and the ability of the end- users to report their arrival and position to the optimization-harmonization system using specialized application on their mobile devices or computers. Such an 


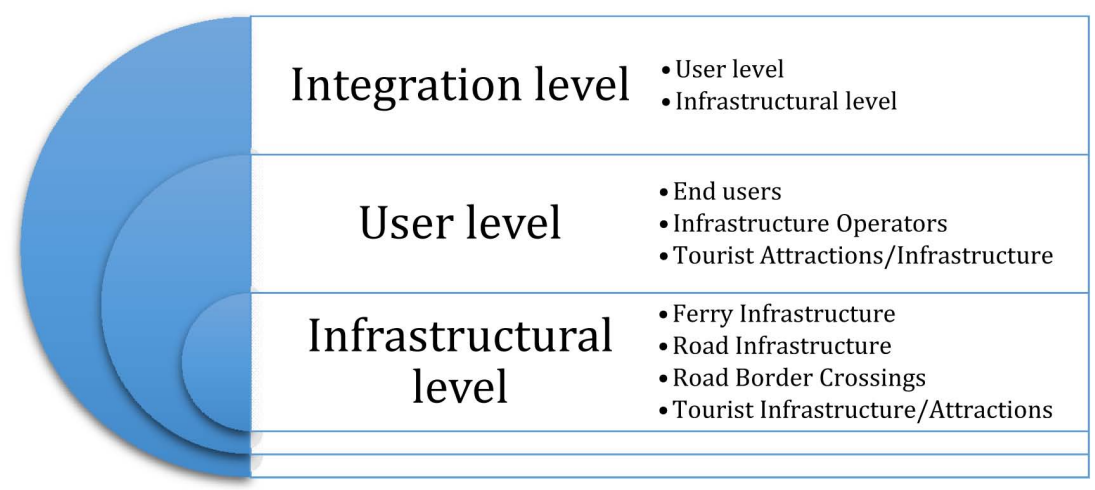

Figure 2 Logical classification of the systems' technological elements

Source: Authors

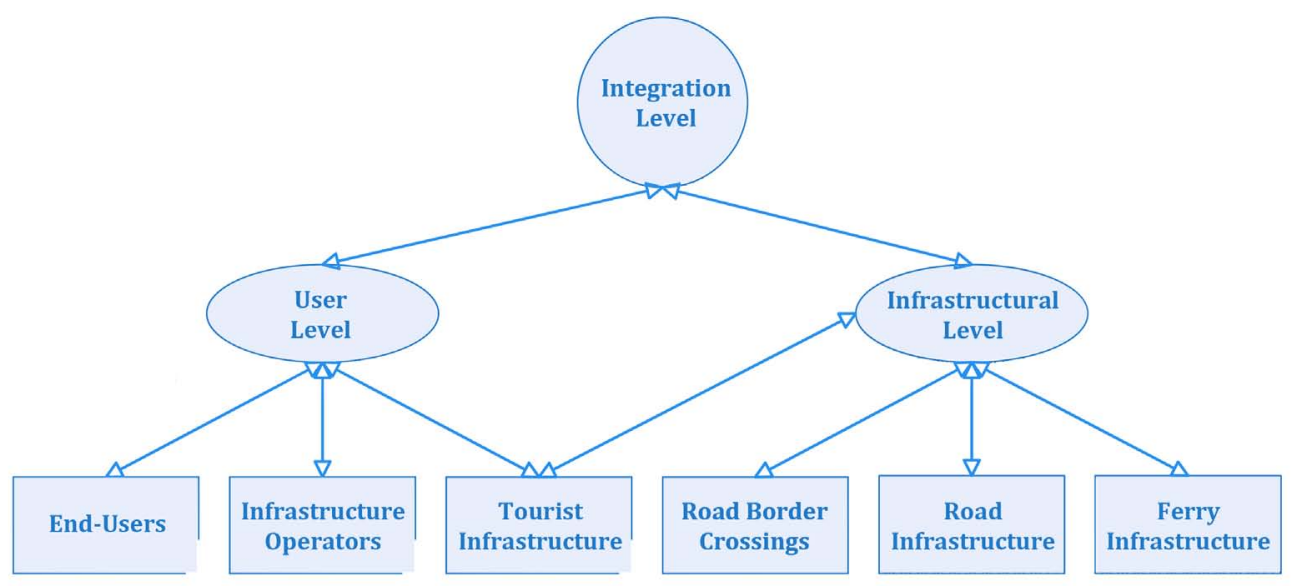

Figure 3 Relational connectivity between optimization system's technological elements

Source: Authors

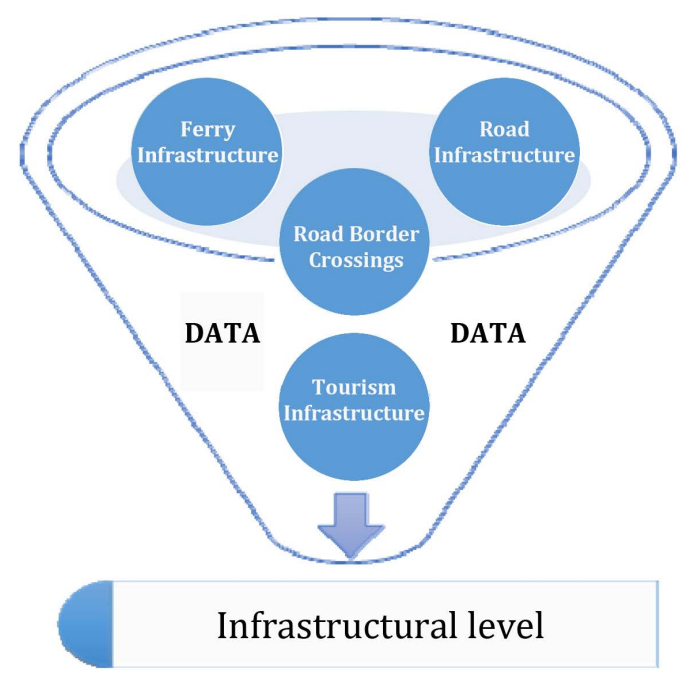

Figure 4 Logical structure of the systems' Infrastructural level 
application offers the ability to check the current state of the queueing at the destination ferry port for each user individually before the beginning of the journey and during the journey. The application obtains the information by determining the users' GPS coordinates, by using data from the road infrastructure and ferry infrastructure load through the existing traffic network monitoring services (Google Maps, OpenStreetMap, Microsoft Bing, etc.) or by the monitoring systems operated by Croatian roads Ltd. (Hrvatske ceste d.o.o. - HC) and Croatian Motorways Ltd. (Hrvatske autoceste - HAC) which are responsible for the operation and maintenance of the road transport network in the Republic of Croatia. Previous research [17] has provided evidence for end users'acceptance of such an application. But at the infrastructural level, the system cannot yet process this information as it requires other two technological elements to achieve full functionality.

Therefore, pursuant to Figure 2 and Figure 3 next required technological element of the proposed optimization model is the user level which consists of two subsystems (Figure 5):

- End-Users' subsystem and

- Infrastructural users' subsystem.

The end-user subsystem is aimed at communicating with the users which are in the model referred to as road vehicles or entities that use the analysed infrastructural capacity. Simultaneously, they provide the system with the information on their destination port, planned time of boarding and their geographical position (i.e. GPS). When determining the position of the road vehicles, at this level, the optimization system can recognize whether the user request has been sent from the Republic of Croatia or outside its borders, in order to provide the end-user with the additional information on the situation at the border crossing(s). In accordance with the received users' (both End- and Infrastructural users) data, the optimization system gathers data and information from all the infrastructural elements (road border crossings, road, ferry and tourist infrastructure) and prepares them for processing at the integration level to be able to provide the users with the information they have requested. In addition, the User level forwards the information to the Integration level to provide data on the queues and waiting times at the destination ports and to offer the possibility of visiting some of the tourist destinations or attractions (infrastructure) located along the road route between the road border crossing and the destination port. This way, the end-users are given the opportunity to have a more pleasant trip and an additional tourist experience by using some benefits such as purchasing tickets for some tourist attractions at the preferential fare, priority ferry boarding (with the minimum or no waiting time).

Apart from sending data on the current ferry infrastructure load, proposed model would offer the service of optimisation of the available ferry capacities in a particular port or berth off the peak load period by using data and information collected from end-users and infrastructural elements (Figure 4). However, when considering the elements of the system that would enable the optimization, with the objective of increasing the availability of the ferry infrastructure capacity, one should take into account the system's peak period when there are no unused ferry capacities, and no increase in capacity is possible. These results have been collected during the process of the model simulation [17] leading to a conclusion that a certain degree of optimization of the ferry capacity utilization could be achieved off the peak period.

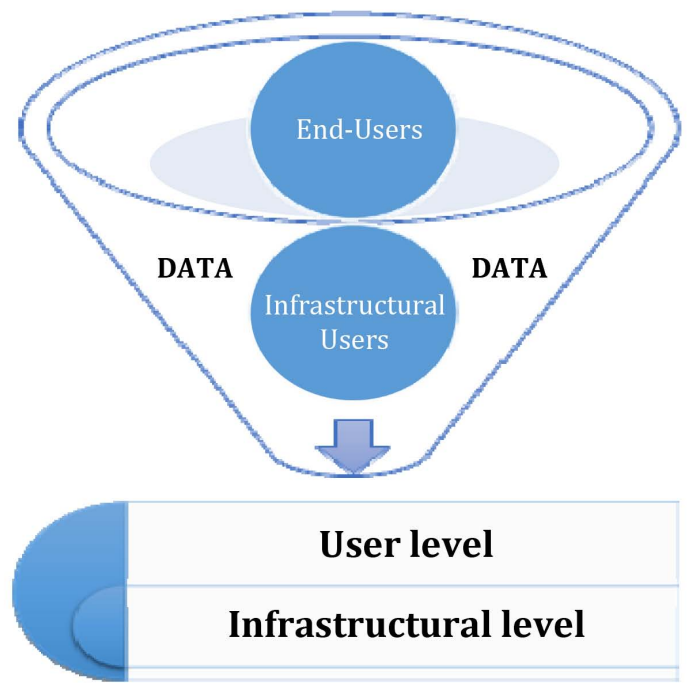

Figure 5 Logical structure of the User level system 


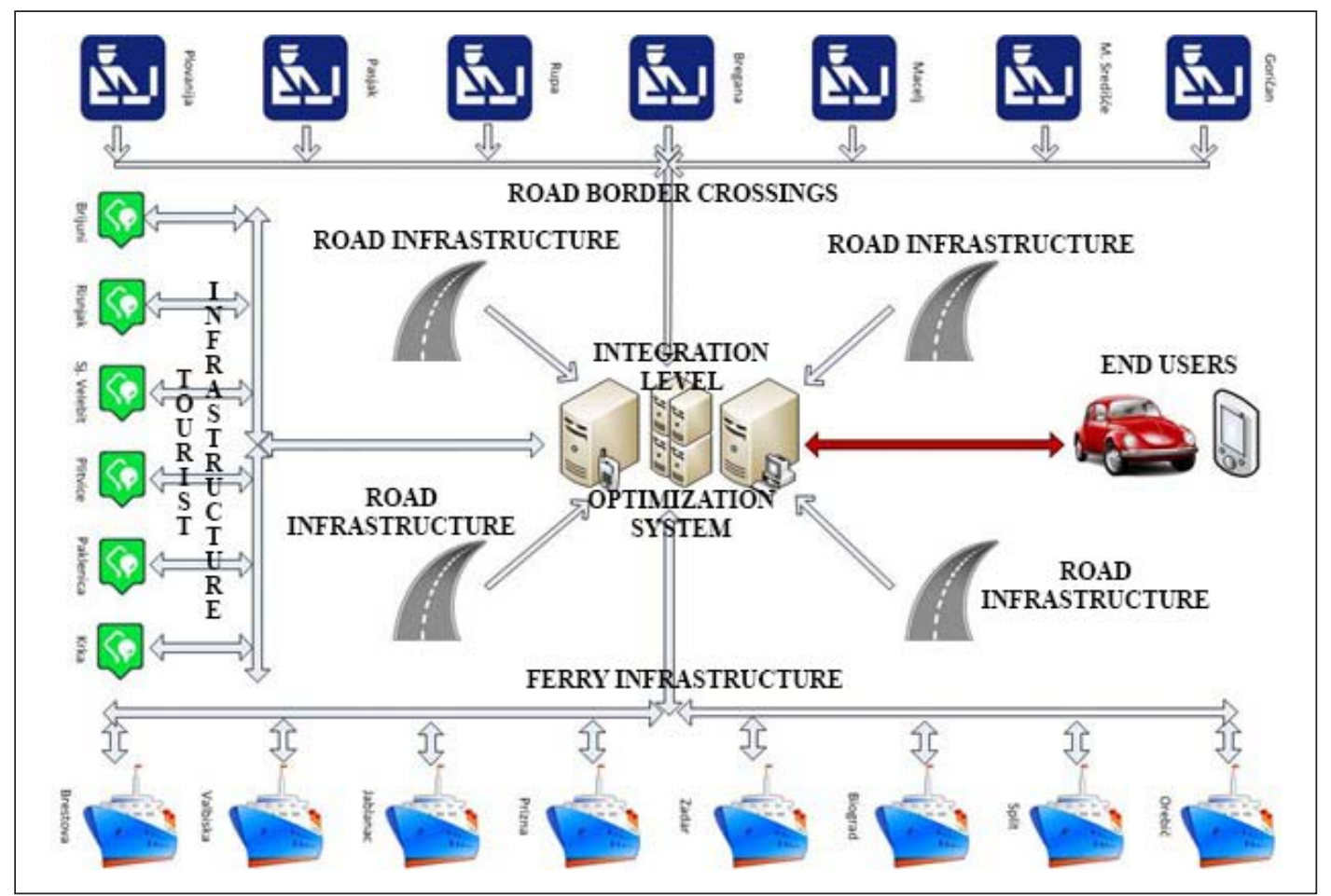

Figure 6 Representation of the proposed optimization system with underlaying elements

Source: Authors

The Integration level, shown in Figure 6, actually represents proposed model of the optimization system whose task is in accordance with its title: the integration of services, i.e. data and information provided and requested by the model's subsystems, and distribution of information to these subsystems through client - server model. The Integration level sends information on the ferry infrastructure free capacity, waiting boarding time, and the possibilities of avoiding queues by redirecting the end-users to some of the alternative or side route tourist facilities or attractions, thus offering them the benefit of avoiding ferry-queue waiting line in case they decide to do so.

The function of the Integration level implies sending feedback to the Infrastructural level, which enables the optimization of the ferry infrastructure management, i.e. the possible allocation of the limited ferry capacity according to the current needs and the system load.

\section{Analytical illustration of the ferry infrastructure demand optimization and harmonization system model}

The flowchart shown in Figure 7 illustrates an overview of the optimization system operation logic at the End-User level. The described logic of work is based on the classic client - server model and begins with the access connection (sending a request) of the end-user with his current GPS coordinates and the destination port (ferry port or berth). In the next step, each user's request is assigned a unique identifier, which allows further monitoring and processing of the user's request in the system. Based on the sent or received data on position and destination, the system processes the data and provides information on the travel route, and the current state of waiting boarding time at the destination ferry port. The data needed to process and generate the requested information into the system are received by the infrastructural users. In the next stage, the system provides the user with information about the route and the estimated travel time to the destination and allows the user the access to the tourist destination offers and attractions that are close to a travel route. If the user does not accept the offer, the user's connection to the system is interrupted and the user does not acquire the right to privileges during the ferry boarding. Otherwise, the system sends the user information and offers for the contents that are located along the planned travel route.

In the following stages, the system continues to display offers until all the available offers are displayed or until the user selects one of the displayed offers. If the user does not select any of the offers, the connection to the system is terminated and the user does not exercise the right to priority in ferry boarding. If the user selects one (or more) of the displayed offers, the system initiates the process of electronic payment of the accepted offer(s) with the simultaneous possibility of providing certain benefits (discounts) on the ferry ticket price, the right of priority boarding, and other benefits. After the billing process has 


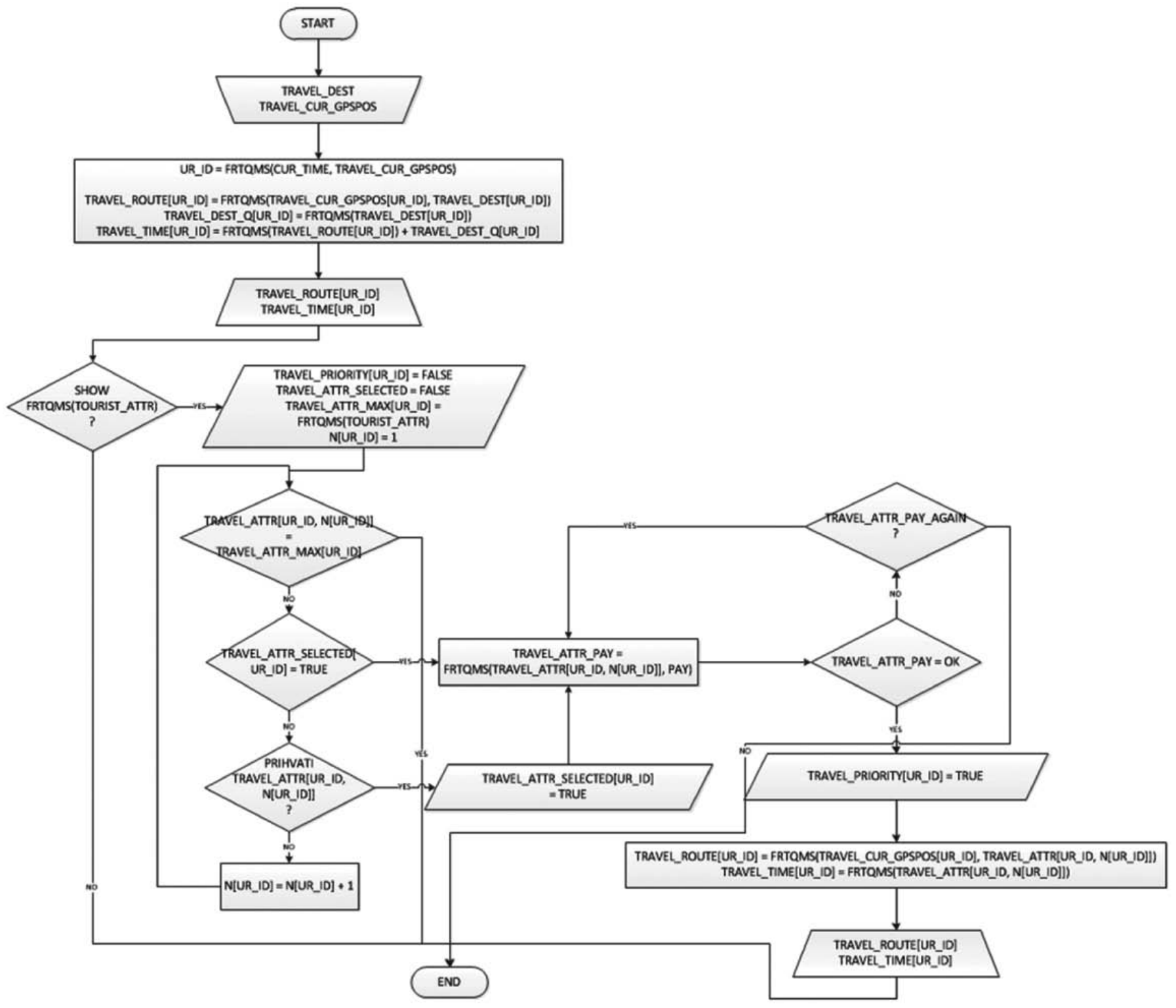

Figure 7 The end-users requests chart flow diagram towards the ferry infrastructure demand optimization and harmonization system

Source: Authors

successfully been completed the system generates new information, processes the data on the new route and travel time, which includes the accepted offer(s), and delivers the specified information to the end-user.

\section{Preconditions for the development of the ferry infrastructure demand optimization and harmonization system}

Since the proposed conceptual model of the ferry infrastructure demand optimization and harmonization system does not imply an increase in the number of currently available ferries, the elements required for the system development primarily refer to financial resources needed to develop missing system elements and improve the operation of the existing elements by their full integration through the proposed system. According to the logical structure of the model shown in Figure 6, looking from the top to the bottom of the model, it is necessary to connect the system of monitoring the number of vehicle entries into the Republic of Croatia at road border crossings, database of the tourist facilities (infrastructure), the ferry infrastructure load, communication and processing of inquires received by the system's end-users. According to the information collected from the relevant institutions and companies (The Ministry of the Interior of the Republic of Croatia, Jadrolinija, Hrvatske ceste Ltd., Croatian Motorways Ltd./Hrvatske autoceste - HAC), it is possible to conclude that all these systems already exist, but they differ in the degree of their development, given 
the interest institution(s) in charge of their development and maintenance.

The current stage of development of these subsystems requires investing in the development of the end-user application for the purpose of communication with the endusers, primarily through various types of mobile devices (e.g. Android, iOS) and/or personal computers. It is also necessary to invest in the computer equipment in charge of the integration of all subsystems. Furthermore, it is necessary to adjust the existing offer of tourist facilities, through which potential tourist places could present their offer to the end-users and provide a feedback on their current capacity and the achieved effect of offers distributed through the system. It is essential to update the system continuously with the ferry infrastructure operator's database and data on the number of vehicle entries at road border crossings into the Republic of Croatia.

Considering the infrastructural investments in computer and application equipment, it is important to mention that they are based on already developed and widely available technologies, where it is not necessary to invest in their development, but only ensure a satisfactory level of operability. The lack of need to develop this component of the system, as the most financially demanding category, greatly reduces financial resources requirements. Furthermore, the integration of all the mentioned subsystems can also be performed using the existing Internet security protocols for data exchange, using also the existing communication network.

Finally, the functionality of the system requires certain financial resources, which, depending on the needs and demonstrated effects of the system, could be funded from the fees for using the system for distributing offers, accomplished results or from a lump sum. When determining the model of financing, one must bear in mind that all the services for the end-users should be free of charge in order to motivate them to use the system as much as possible.

\section{Conclusion}

The application of the proposed optimization - harmonization system model would have multiple positive effects on all involved parties - the end-users, the infrastructural users, and the tourist offer, especially as conducted survey [18] confirmed end-users' acceptance of proposed ticketing system. The end-users would be able to plan trips, with the minimal or no waiting boarding time which would be an added value for the tourist perception of the Republic of Croatia because of the possibility of visiting some tourist destinations proposed by the system. This primarily implies various possibilities of cumulative prices of the ferry services and the price of tickets for tourist facilities. Thus, it is possible for the endusers who decide to use the system's offer, to use the ferry preferential rates, possibly at slightly higher price of the ferry transport in the case of exercising the right to priori- ty boarding. Furthermore, it is possible to offer a combination of the regular ticket prices of the tourist facilities, and a reduced price of the ferry transport in case the user does not want to exercise the right of priority boarding. Also, it is possible that the end-user decides to spend the night in tourist destination that provide such an opportunity (e.g. Plitvice Lakes National Park), and thus generate additional revenue to the provider of the tourist content, but also directly contribute to creating the added value.

The infrastructural users would be given the opportunity of better road and ferry infrastructure control and management, especially the ferry operators, to whom the system should help identify critical (weather and infrastructural) points of ferry infrastructure where efficiency could be increased. By applying the proposed model, in the case of unequal load of individual ferry ports, the ferry operators could optimize the available capacity by reorganizing and deploying ferry capacity. The queues in ferry ports in cities and town centres could be reduced by harmonizing the traffic flows or relocating them outside the ferry ports. Ultimately, the positive effects of the application of the proposed model of the system would be visible on the increase in the number of visitors to tourist destinations as well as their popularization.

\section{References}

[1] Abdul S., Aziz N. (2019) Investigating the Factors Influencing Travellers' Purchase Intention Via Online Travel Intermediaries Websites, Journal of Advanced Research in Dynamical and Control Systems, Vol. 11, No. 5, pp. 803-812.

[2] Barac L. (2018) Seaport development planning, Master thesis, Faculty of Maritime Studies Split.

[3] Brandao M. (2017) The transformation process of an international tourist destination into a Smart City under the ANT's lens: The case of Búzios Cidade Inteligente, ENTER2017 eTourism Conference - PhD Workshop Research Proposals, Rome.

[4] Delac L. (2019) Analysis of liner maritime traffic with special reference to the Republic of Croatia, Master thesis, Faculty of economics and business Zagreb.

[5] Government of the Republic of Croatia, Maritime Development Strategy and Integrated Maritime Policy of the Republic of Croatia for the period from 2014 to 2020, Source: <https://vlada.gov.hr/UserDocsImages//ZPPI/Strategije\%20-\%200GP/promet//POMORSKA\%20STARTEGIJA\%20VRH\%202207201\%20web\%2026-7_14.pdf >.

[6] Government of the Republic of Croatia, Transport Development Strategy of the Republic of Croatia for the period from 2017 to 2030, Source: <https://vlada.gov.hr/UserDocsImages / / ZPPI / Strategije / / M M PI\%2 02017 -2030\%20 STRAT\%20PROM\%20RZV\%20RH\%2025-8_17.pdf>.

[7] Lai I. K. W. (2013) Traveller Acceptance of an App-Based Mobile Tour Guide, Journal of Hospitality \& Tourism Research, Vol.39, No.3, pp. 401-432.DOI: 10.1177/1096348013491596.

[8] Law R., Chan C. C. I., Wang L. (2018) A comprehensive review of mobile technology use in hospitality and tourism, Journal of Hospitality Marketing \& Management, Vol. 27, No. 6, pp. 626-648. DOI: 10.1080/19368623.2018.1423251. 
[9] Law R., Laung D., Chan C. C. I. (2020) Progression and development of information and communication technology research in hospitality and tourism: A state-of-the-art review, International Journal of Contemporary Hospitality Management, Vol. 32, No. 2, pp. 511-534, DOI: 10.1108/IJCHM-072018-0586.

[10] Mrvica A. (2015) Rationalisation of the maritime connections between the mainland and the islands as well as of those between the islands in the Republic of Croatia, PhD thesis, Faculty of Maritime Studies Rijeka.

[11] Navio-Marco J., Ruiz G. L. M., Sevilla-Sevilla C. (2018) Internet and Consumer behaviour in Travel and Tourism: A European Cross-National Analysis, Journal of Reviews on Global Economics, Vol. 7, pp. 186-194.

[12] Palau-Saumell R., Forgas S., Sánchez-García J., Robres E. (2019) User Acceptance of Mobile Apps for Restaurants: An Expanded and Extended UTAUT-2, Sustainability, Vol. 11, No. 4, 1210, DOI: 10.3390/su11041210.

[13] Pourfakhimi S., Duncan T., Ould L., Allan K., Coetzee W. (2020) Acceptance and adoption of eTourism technologies, In: Xiang Z., Fuchs M., Gretzel U., Höpken W. (eds) Handbook of e-Tourism, 1-31, Springer, Cham., DOI: 10.1007/978-3030-05324-6_58-1.
[14] Rasinger J., Fuchs M., Höpken W. (2007) Information Search with Mobile Tourist Guides: A Survey of Usage Intention, Information Technology \& Tourism, Vol. 9, No. 3-4, pp. 177194. DOI: $10.3727 / 109830507782166962$.

[15] Toman I., Kos, S., Brcic D. (2018) Structural Analysis of Relevant Parameters of Coastal Line Zadar-Preko: Trends and Optimization Possibilities, Pomorski zbornik - Journal of Maritime and Transportation Sciences. Vol. 55, No. 1, DOI: 10.18048/2018.00.06.

[16] Zupanovic D. (2015) Implementation Model for Near Field Communication in Croatian Ferry Ticketing System, Procedia Engineering, Vol. 100, pp. 1396-1404, DOI: 10.1016/ 2015.01.509.

[17] Zupanovic D., Pejdo A., Mirosevic L. (2017) Simulation of ferry queue management system in Croatia, Tehnički vjesnik - Technical Gazette, 24 (2), pp. 485-494.

[18] Zupanovic D. (2011) Ferry ports infrastructural capacity advanced management system, Master thesis, Faculty of Economics \& Business, Zagreb.

[19] EUROSTAT, Maritime ports freight and passenger statistics (2020) Source: <https://ec.europa.eu/eurostat/statisticsexplained/index.php/Maritime_ports_freight_and_passenger_statistics\#Most_EU_seaborne_passenger_transport_is_ within_national_borders>. 